\title{
UNUSUAL LOCATION OF CYSTICERCOSIS LESION PRESENTATION
}

Dr. V. Geeta, Dr. Parimla Devi, Dr. A. Sirisha, Dr. Rama Devi, Dr. Jijiya Bai, Dr. Shravan Kumar

1. Assistant Professor, Department of Pathology, Gandhi Medical College, Secunderabad-6

2. Associate Professor, Department of Pathology, Gandhi Medical College, Secunderabad-6

3. Assistant Professor, Department of Pathology, Gandhi Medical College, Secunderabad-6

4. Assistant Professor, Department of Pathology, Gandhi Medical College, Secunderabad-6

5. Professor and HOD, Department of Pathology, Gandhi Medical College, Secunderabad-6

6. Professor, Department of Pathology, Gandhi Medical College, Secunderabad-6

\section{CORRESPONDING AUTHOR:}

Dr. V. Geeta,

Assistant Professor,

Department of Pathology,

Gandhi Medical College,

Secunderabad-6

Email ID- geetavoolapalli@gmail.com

\section{INTRODUCTION:}

Cysticercosis in humans is exclusively caused by larvae of T.solium which have predilection for skeletal muscle, eyes, and central nervous system. In literature head and neck manifestations of Cysticercosis is reported as soft tissue swellings at sub mental area, cheek as well as tongue ${ }^{1-4}$. Cysticercosis presenting as a nodule or mass on neck is a very rare occurance ${ }^{5}$. The diagnosis was usually made on Histo pathologic examination. The ensuing clinical disorder is named after the organism at this larval stage, cysticercosis cellulose Larva of pork tapeworm Taenia solium.

KEY WORDS: Cysticercosis, T.solium

\section{CASE HISTORY:}

A 21 years male presented with a painless solitary nodular swelling on right side of the upper neck of 2 years duration. The nodule was gradually increasing in size, associated with anxiety, easy fatigability, palpitations, decreased appetite and weight loss.

Local examination revealed $2 \times 2 \mathrm{~cm}$ round, smooth swelling present on right side of neck at the level of Thyroid cartilage and anterior to the upper $1 / 3^{\text {rd }}$ of sternocleido mastoid muscle and on palpation the swelling is cystic, non tender, firm in consistency, not moving with deglutition and on protrusion of tongue.

Skin over the swelling was non pinchable. No local rise in temperature. Swelling was mobile both horizontally and vertically, not attached to the underlying muscle. General and systematic examination within normal limits.

Clinical Diagnosis made was

1) Benign cystic swelling of right neck.

Journal of Evolution of Medical and Dental sciences/ Volume 1/ Issue 3/ July- Sept 2012 

2) Sebaceous cyst
3) Lipoma
4) TB lymph node
5) Aberrant thyroid
6) Salivary gland

FNAC: S/o '?' necrotic lymph node, complex cyst or parasitic cyst. U/S: S/o '?' necrotic lymph node

Excision of the cyst was done and sent for HPE

The Histopathologic examination revealed 'Cysticercosis Cellulose' characterized by a scolex and epithelium lined by tortuous body and continuous with outer cystic layer. Cyst enclosed by a fibrous capsule infiltrated with lymphocytes, plasma cells and eosinophils. Figure.1

The post operative period was uneventful.

\section{DISCUSSION:}

Taenia solium passes its life cycle in two hosts. The definitive host is human who harbors the adult worm and intermediate host in pig which harbors the larval stage. The adult worm lives in the small intestine of man. Usually one adult worm is present which lives for years. It is about 3 meters long with proglotids, the gravid segments with about 50000 eggs in each gravid segment. The worm sheds gravid segments laden with eggs in the stools which infect pigs on reaching the alimentary canal of the intermediate host penetrate the gut wall and reach systemic circulation and are lodged in different organs and muscles. They develop in to larvae referred as cysticercosis Human being are infected through eating under cooked contaminated pork or infected vegetables. Adult worms shed gravid segment laden with eggs in the stool, which re infect pigs. Thus completing the cycle. Autoinfection of man may occur by contaminated fingers or by reversal of peristaltic movements of intestine, the gravid segments are thrown back to the stomach and larvae disseminate throughout the body via Arterio Venous Channels and lymphatics encysting in subcutaneous tissue, striated muscle, brain and ocular tissue ${ }^{6}$.

Cysticercosis manifestations are different and depend on the location in the body and also number of cysticercosis of a particular site and associated inflammatory response. 87\% cysticercosis cases - presents as solitary or multiple subcutaneous nodules on the trunk, upper arm, neck, tongue, face and breast has been reported in this order of frequency.

In many patients involvement of central nervous system in the form of neuro Cysticercosis is diagnosed when multiple cystic ring enhancing parenchymal lesions has been detected on CT Scan ${ }^{7}$. We are not reporting this case because of its unusual site of presentation, but also the importance of histopathologic examination is emphasized since neither the clinical examination nor history suggested the diagnosis other than a benign lesion.

Journal of Evolution of Medical and Dental sciences/ Volume 1/ Issue 3/ July- Sept 2012 


\section{CASE REPORT}

Photo micrographs showing cystic lesion containing parts of parasite and the cystic wall containing granulation tissue with inflammatory reaction.
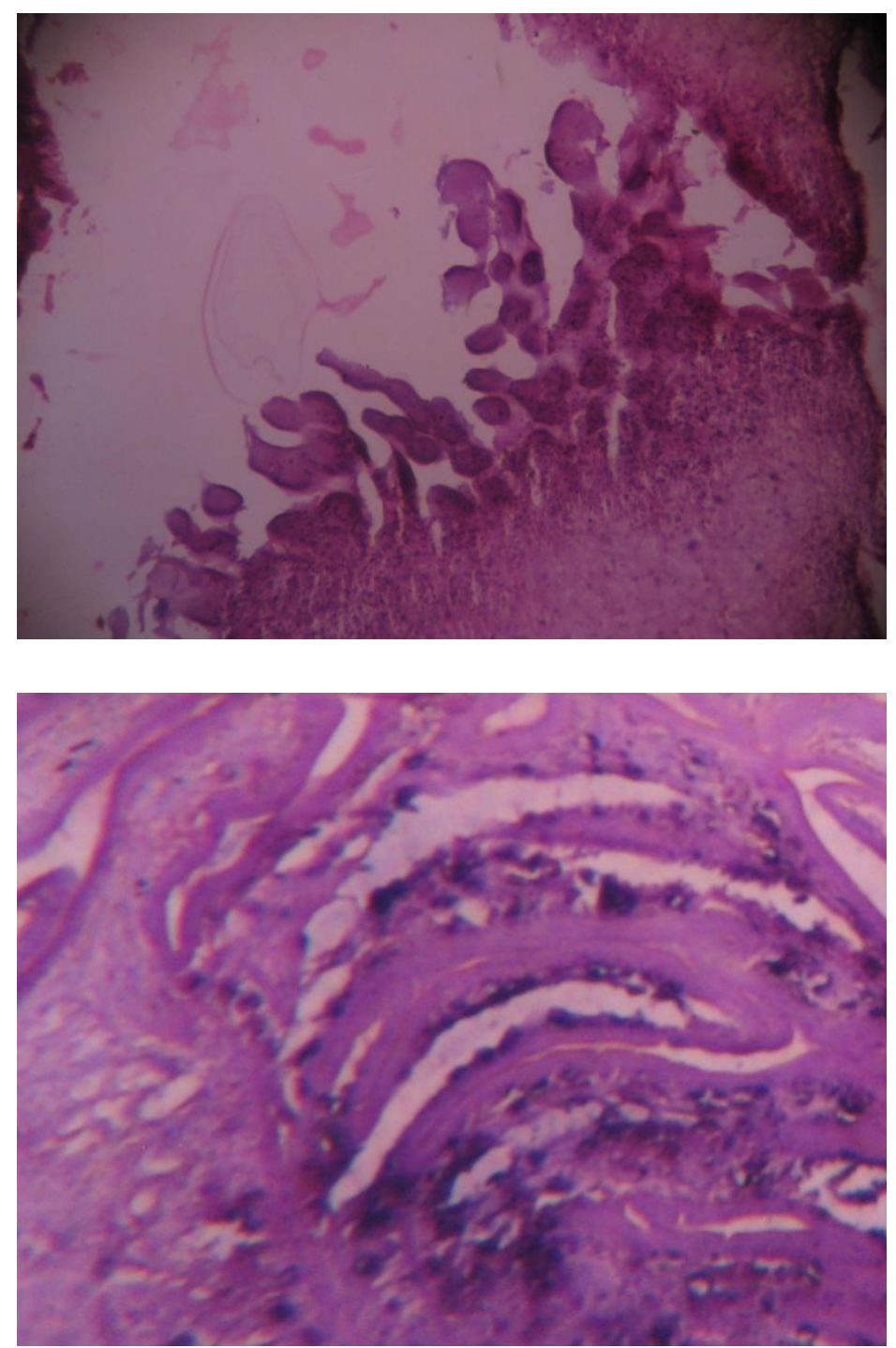

\section{REFERENCES:}

1. Kinnman J, Chi CH, Park JH. Cysticercosis in Otolaryngology. Arch Otolaryngol 1976; 102:144-7

2. Beaver PC, Jung RC, Cupp EW. Clinical Parasitology, 9 th edition. Philadelphia: Lea \& Febiger, 1984.

3. Jain RK, Gupta OP, Aryya NC. Cysticercosis of the tongue. J Laryngol Otol 1989; 103:1227-8

4. Gupta SC and Gupta SC. Cysticercosis of the tongue. Ear Nose Throat J 1995;74:174-8

Journal of Evolution of Medical and Dental sciences/ Volume 1/ Issue 3/ July- Sept 2012 


\section{CASE REPORT}

5. Cysticercosis of the neck-a report of unusual case. Danai Tanechpongfamb, dept.of oto rhino laryngeology; Pathum thani Hospital, Journal of Medicine and health sciences, faculty of medicine, srinakharin wirat university, Vol. 12, No.2, Aug-2005.

6. Park K. Epidemiology of Communicable diseases. In: Park K. Park's Textbook of Preventive and Social Medicine. 16 th ed. New Delhi: M/s Banarsidas Bhanot Publishers, 2000; 229.

7. Smiti S, Sripathi H and Naik L. Unusual location of cysticercosis lesions in soft tissue Report of three cases. Ind J Radiol Imag 2003;13:157-8 